\title{
Behavioural and reflex responses of mottled mojarra Eucinostomus lefroyi (Gerreidae) to cold shock exposure
}

\author{
Emma Samson, Jacob W. Brownscombe*, Steven J. Cooke \\ Fish Ecology and Conservation Physiology Laboratory, Ottawa-Carleton Institute for Biology, Carleton University, \\ 1125 Colonel By Dr., Ottawa, ON K1S 5B6, Canada
}

\begin{abstract}
Global climate change is predicted to increase incidences of abrupt declines in oceanic temperatures due to storms or upwelling. Fish occupying shallow, near-shore marine habitats may be vulnerable to mortality or sub-lethal fitness effects due to cold shock. Mottled mojarra Eucinostomus lefroyi are a ubiquitous prey species associated with subtropical and tropical coastal habitats and thus serve as a model for evaluating the consequences of cold shock events. Here, we conducted one of the first studies of cold shock on a tropical-subtropical fish species. Fish acclimated to $24^{\circ} \mathrm{C}$ were exposed to acute temperature drops to 16 , 18 , or $20^{\circ} \mathrm{C}$ for $1 \mathrm{~h}$. Ventilation rates were assessed every 15 min during exposure, and equilibrium loss every 5 min. Thirty minutes after cold shock exposure, fish were placed in a circular swim flume and chased by hand until exhaustion to measure chase time and distance chased as proxies for swimming capabilities. Fish exposed to 18 and $20^{\circ} \mathrm{C}$ had significantly higher ventilation rates than those exposed to $16^{\circ} \mathrm{C}$ or controls held at $24^{\circ} \mathrm{C}$. Exposure to 16 and $18^{\circ} \mathrm{C}$ caused reflex impairment (e.g. no response to tail grabbing), while exposure to $20^{\circ} \mathrm{C}$ caused no impairment. After 30 min of recovery at ambient temperature, no reflex impairments were detected in any of the treatments, and the swimming capabilities of fish exposed to cold shock were similar to, or better than control fish. Our findings suggest that abrupt changes in water temperature $>4^{\circ} \mathrm{C}$ below ambient can cause behavioural impairments that may lead to mortality in this species.
\end{abstract}

KEY WORDS: Cold shock · Thermal biology · Subtropics · Mottled mojarra · Reflex Action Mortality Predictors · RAMP

\section{INTRODUCTION}

Temperature has been described as the 'master' abiotic factor for fish (Brett 1971) given its manifold effects on behaviour, biochemical processes, locomotion, bioenergetics, growth, life history, and cardiorespiratory physiology. In subtropical and tropical habitats, fish are adapted to a more narrow temperature range in comparison to their temperate counterparts (Larsen et al. 2011), which suggests that tropical fish species may be more sensitive to large fluctuations in ambient water temperature. Further, climate change is predicted to increase the intensity of extreme weather conditions such as tropical cy-

\footnotetext{
*Corresponding author: jakebrownscombe@gmail.com
}

clones and heavy precipitation events (Michener et al. 1997), which will likely cause sudden declines in ambient water temperature, particularly in shallow waters (IPCC 2007). Moreover, coastal upwelling may become more intense, transporting cooler, deep waters to coastal areas (Bakun 1990). In the context of climate change, most efforts have been devoted to considering the biological consequences of warming waters (Roessig et al. 2004), but sudden decreases in water temperature are also relevant. For example, in Butternut Cay, Florida, USA, in January 2010 water temperatures declined $11^{\circ} \mathrm{C}$, from 19 to $8^{\circ} \mathrm{C}$, resulting in a large fish kill for many near-shore dwelling species (FWCC 2010, A. Adams pers. comm.).

() The authors 2014. Open Access under Creative Commons by Attribution Licence. Use, distribution and reproduction are unrestricted. Authors and original publication must be credited. 
There are numerous studies examining the effects of an increase in temperature on tropical marine fish (e.g. Munday et al. 2008, Nilsson et al. 2009, Donelson et al. 2011), yet virtually no research on the effects of decreases in water temperature, including the phenomenon known as cold shock (LamadridRose \& Boehlert 1988, Donaldson et al. 2008, MeyerRochow 2013). Studies focusing on temperate freshwater species, such as rainbow trout Oncorhynchus mykiss, have found that they can adapt physiologically to ecologically relevant acute or chronic cold water exposure (Shiels et al. 2003, Haverinen \& Vornanen 2007). Yet for tropical marine fish, even basic information on thermal tolerances (especially lower) is rare (Fangue \& Bennett 2003, Eme \& Bennett 2009, Murchie et al. 2011). There is a need for more information on the effects of thermal change, including cold shock, on tropical marine fish (Wilson et al. 2010).

Cold shock in fish occurs when the temperature suddenly drops below a level the fish is acclimated to (Donaldson et al. 2008, Meyer-Rochow 2013). Previous research, largely on freshwater fish, has shown that cold shock may cause both behavioural and physiological consequences, in addition to fatalities (Fry 1947, reviewed in Donaldson et al. 2008). Inhibition of the spinal reflexes often occurs (Roots \& Prosser 1962), which reduces the individuals' swimming abilities, eventually leading to a loss of equilibrium (Lamadrid-Rose \& Boehlert 1988). The cause of this inhibition appears to be a result of effects of cold temperatures on the hypothalamic-pituitaryinterrenal axis and the brain (Donaldson et al. 2008). An experiment on the tropical species Mugil cephalus revealed that a cold shock $15^{\circ} \mathrm{C}$ below ambient resulted in many individuals losing equilibrium, and $75 \%$ mortality (Lamadrid-Rose \& Boehlert 1988). In addition to spinal reflexes, other conditioned reflexes appear to become impaired. Such inhibition, however, is reversible if the fish survive the temperature change (Prosser \& Farhi 1965, Montgomery \& Macdonald 1990) and return to ambient water. The loss of equilibrium and reflex impairment is a particularly important factor for prey species. If the tolerance of prey species to cold shock is lower than that of their predators, it puts the prey species at risk due to reduced predator avoidance capabilities (LamadridRose \& Boehlert 1988).

Mottled mojarra Eucinostomus lefroyi inhabit shallow subtropical and tropical marine waters on the east coast of North America, where they (along with congenerics) are a major component of fish communities in estuaries and coastal habitats (Kerschner et al. 1985). They are a prey species for predators such as lemon sharks Negaprion brevirostris, for which mojarra species were found to compromise over $50 \%$ of the consumed prey biomass in a study carried out in 2003 at Bimini, The Bahamas (Newman et al. 2012). Since temperature fluctuations in shallow waters may be more extreme than in deeper waters (IPCC 2007), mottled mojarra may experience more frequent and more extreme temperature decreases in the future. Therefore, it is important to understand the effects of such decreases on the behaviour and physiological responses of the species, and whether their tolerance is within the threshold of the predicted decreases. Given their large distribution, the fact that mottled mojarra or other similar smallbodied fishes are so prominent in coastal tropical marine systems, and the apparent important role of such fish in marine food webs, research on the effects of cold shock on such fishes is warranted (Kerschner et al. 1985).

The objective of this study was to examine the sensitivity of mottled mojarra to cold shock exposure, by (1) determining the critical thermal (CT) minimum temperature for the species and (2) measuring the effects of a range of ecologically relevant, abrupt temperature declines on the behaviour, ventilation rate and reflex responses. We aimed to determine cold shock tolerance thresholds and relevant behavioural responses of an ecologically important nearshore marine fish, which may serve as a model for understanding the potential effects of this stressor on similar species.

\section{MATERIALS AND METHODS}

\section{Fish collection}

A total of 64 mottled mojarra $(89 \pm 7 \mathrm{~mm}$ total length, TL; range 75 to $100 \mathrm{~mm}$ ) were collected by seine net from shallow sandy habitats in Kemps Creek (244ㅇ $\left.48^{\prime} 54.29^{\prime \prime} \mathrm{N}, 76^{\circ} 18^{\prime} 03.09^{\prime \prime} \mathrm{W}\right)$ and Page Creek $\left(24^{\circ} 49^{\prime} 4.7^{\prime \prime} \mathrm{N}, 76^{\circ} 18^{\prime} 51.6^{\prime \prime} \mathrm{W}\right)$, and transported to a holding tank at the Cape Eleuthera Institute in Eleuthera, The Bahamas on 15 January 2013. Water temperature at time of capture ranged from 23 to $25^{\circ} \mathrm{C}$. Fish were held for $24 \mathrm{~h}$ prior to examination in circular tanks $(3.7 \mathrm{~m}$ diameter $\times 1.25 \mathrm{~m}$ height, 13180 l) with $1 \mathrm{~m}$ water depths, supplied with constant flow of fresh seawater. The seawater intake was from $1.5 \mathrm{~m}$ of water such that the water temperature was stable $\left(\sim 24^{\circ} \mathrm{C}\right.$ during the study period) despite more extreme diel thermal variation in the nearshore tidal creeks from which the fish were captured. 


\section{CT minimum}

Mottled mojarra $(\mathrm{n}=14)$ were exposed to a linear temperature decrease $\left(\sim 0.2^{\circ} \mathrm{C} \mathrm{min}^{-1}\right)$ in individual aerated $1 \mathrm{l}$ containers (containing $750 \mathrm{ml}$ of seawater) from ambient temperature $\left(24^{\circ} \mathrm{C}\right)$ until equilibrium was lost, following the methods of Murchie et al. (2011). Two separate trials were conducted with 7 fish in each. Fish were considered to have lost equilibrium when they were unable to maintain upright posture for a minimum of $5 \mathrm{~s}$, at which point time to loss was recorded. Determination of CT minimum was needed to inform the design of subsequent experiments. That is, our interest was in sub-lethal outcomes, so we needed to identify the level of lower thermal tolerance of this species.

\section{Cold shock}

Cold shock trials were conducted from 09:00 to 18:00 h from 16 to 29 January 2013. Each trial consisted of 8 fish, all kept in water of the same temperature, with 2 trials for each treatment (16 fish in total). Trials alternated randomly amongst treatments, which consisted of 16,18 , and $20^{\circ} \mathrm{C}$ temperatures (all below ambient temperature), and controls that remained at ambient temperature $\left(24^{\circ} \mathrm{C}\right)$.

To begin trials, individual opaque plastic containers (1 l volume) were filled with $750 \mathrm{ml}$ of seawater at ambient temperature. A small air stone was placed in each container to provide oxygen and ensure that the water was well mixed. Containers were then partially submerged in an ice bath (100 l cooler), or in the case of the controls, ambient seawater. For cold shock treatments, the temperature in the containers was lowered to the desired temperature by managing the amount of ice in the cooler. Once treatment temperatures were attained, mottled mojarra were transferred by dip net from the holding tank into individual containers. Trials were then initiated and lasted for $1 \mathrm{~h}$. Temperature was recorded every $15 \mathrm{~min}$ during trials using a YSI meter (EcoSense pH10 A, Xylem).

During cold shock trials, ventilation rates were recorded by the same observer every $15 \mathrm{~min}$, by visually counting operculum beats for $30 \mathrm{~s}$. Reflex Action Mortality Predictors (RAMP; Davis 2010) were also assessed at the beginning and end of each trial, or at the time of equilibrium loss. A total of 5 RAMP indices were used: tail grab, body flex, head complex, vestibular-ocular response (VOR), and equilibrium. These metrics were chosen because they are strong indicators of vitality in other fish species in the context of fisheries-related stress (Raby et al. 2012, Brownscombe et al. 2013, 2014, Cooke et al. 2014), as well as cold shock (Szekeres et al. 2014). Tail grab was assessed by grabbing the fish's tail by hand, and was considered impaired if the fish did not immediately attempt to swim away. Body flex was assessed by briefly holding the fish out of the water; a lack of attempt to struggle free indicated impairment. While held out of the water, head complex was considered impaired if regular opercular beats were not observed. VOR was assessed by rolling the fish from side to side to determine whether the eyes were able to track the handler. Equilibrium was assessed by flipping the fish upside down in the water, and was considered impaired if the fish failed to recover within 3 s. Higher RAMP scores indicated greater impairment.

Once trials were completed, mottled mojarra were transferred into recovery containers (1 1 volume, containing $750 \mathrm{ml}$ of water) at ambient temperature for $30 \mathrm{~min}$. After this recovery period, fish were transferred individually to 51 circular containers with $8 \mathrm{~cm}$ of water depth, which were divided into 4 equal quadrants by lines drawn on the bottom of the container. Fish were chased by hand until exhaustion by one researcher, while another researcher recorded the number of lines mottled mojarra crossed prior to exhaustion. Fish were considered exhausted when the chaser could touch the fish's tail 3 times without an attempt to escape. RAMP was assessed both immediately before and after chase trials; ventilation rates were measured immediately after. Once completed, the fish were allowed to recover for a minimum of $1 \mathrm{~h}$ before being released into the wild. Although this approach to evaluating swimming ability does not generate an actual swimming speed per se, it does provide a robust approach for making inter-treatment comparisons (Portz 2007).

\section{Statistical analysis}

The relationship between mottled mojarra TL and CT minimum was analysed with Pearson's correlation coefficient. Mottled mojarra ventilation rates were compared between treatments and over time with a linear mixed effect (LME) model with individual fish as a random factor. Significant terms were determined using backwards model selection with log-ratio tests. A variance structure was used to correct for variance heterogeneity (Pinheiro \& Bates 2000). Tukey's HSD post hoc tests were used to deter- 
mine significant differences between treatments. Mottled mojarra RAMP score frequencies were compared among treatments using a chi-squared test for independence. For the chase to exhaustion experiment, the effects of temperature on the number of lines crossed and time chased were analysed using 1way ANOVA. Tukey's HSD tests were used to determine significant differences. Assumptions of normality and homogeneity were tested prior to analysis. Results were considered significant at $p \leq 0.05$, and all analyses were conducted using R studio (R Core Team 2012).

\section{RESULTS}

\section{CT minimum}

The CT minimum (at which mottled mojarra lost equilibrium) was $12.29 \pm 0.75^{\circ} \mathrm{C}$ (mean $\pm \mathrm{SE}$ ). There was no significant association between TL and CT minimum within the size range of 75 to $100 \mathrm{~mm}(\mathrm{r}=$ $0.44, \mathrm{p}=0.56)$.

\section{Cold shock}

During cold shock exposure, mottled mojarra ventilation rates were highly variable among treatments, with fish in both the 16 and $24^{\circ} \mathrm{C}$ treatments generally exhibiting lower ventilation rates than those in the 18 and $20^{\circ} \mathrm{C}$ treatments (Fig. 1). Comparing ventilation rates among treatments and over time, there was a significant effect of time (LME; $F_{1,254}=79.3, \mathrm{p}<$ 0.001 ), and significant interaction between treatment and time $\left(F_{1,254}=16.6, \mathrm{p}<0.001\right)$. At the start of the exposure period, ventilation rates were significantly higher at 18 than at $24^{\circ} \mathrm{C}$ (Tukey's HSD; $\mathrm{p}=0.01$ ). After 15 min of exposure, ventilation rates were significantly higher at 18 and $20^{\circ} \mathrm{C}$ than at $16^{\circ} \mathrm{C}$ (p < 0.01 ). For the remaining time periods (i.e. 30,45 and $60 \mathrm{~min}$ ) ventilation rates were significantly higher at 18 and $20^{\circ} \mathrm{C}$ than at 16 and $24^{\circ} \mathrm{C}(\mathrm{p}<0.05)$.

Prior to the cold shock exposure period, all mottled mojarra had RAMP scores of 0 (no impairment). During exposure, no fish lost equilibrium at 24 or $20^{\circ} \mathrm{C}$, however, $3(19 \%)$ and 9 (56\%) fish lost equilibrium at 18 and $16^{\circ} \mathrm{C}$ respectively (Fig. 2). After the $60 \mathrm{~min}$ exposure period, there was a significant difference in the amount of reflex impairment between treatments $\left(\chi^{2}=44, \mathrm{df}=12, \mathrm{p}<0.001\right)$. While mottled mojarra in the 20 and $24^{\circ} \mathrm{C}$ treatments exhibited no reflex impairment, fish in the 16 and $18^{\circ} \mathrm{C}$ treatments con-

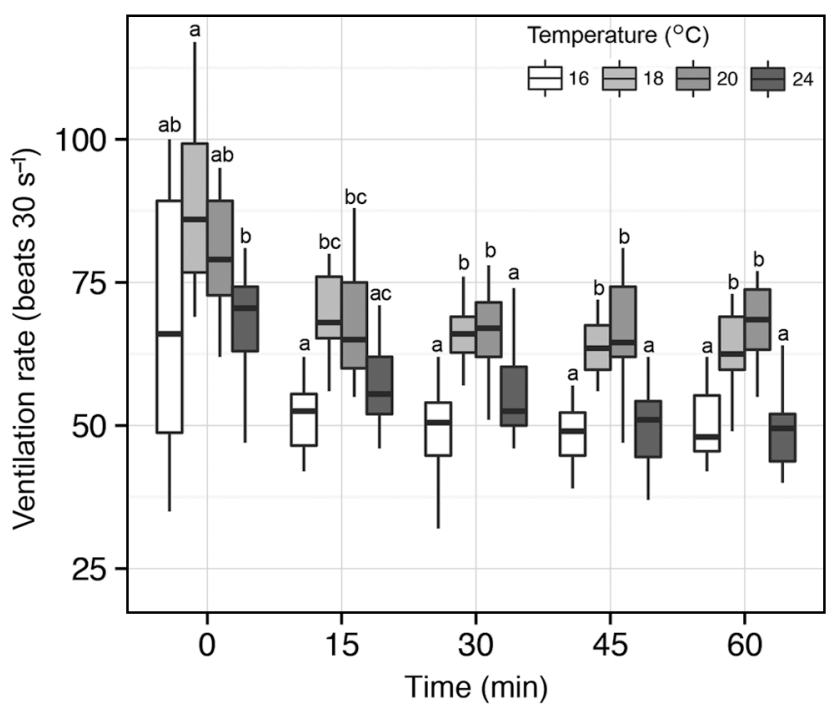

Fig. 1. Ventilation rates (beats per $30 \mathrm{~s}$ ) of mottled mojarra across a range of temperatures for a $1 \mathrm{~h}$ period. Boxes: 1st and 3rd quartiles; horizontal lines: medians; whiskers: $1.5 \times$ inner quartile range; dots: outliers. Dissimilar letters indicate statistically significant differences using Tukey's HSD post hoc test

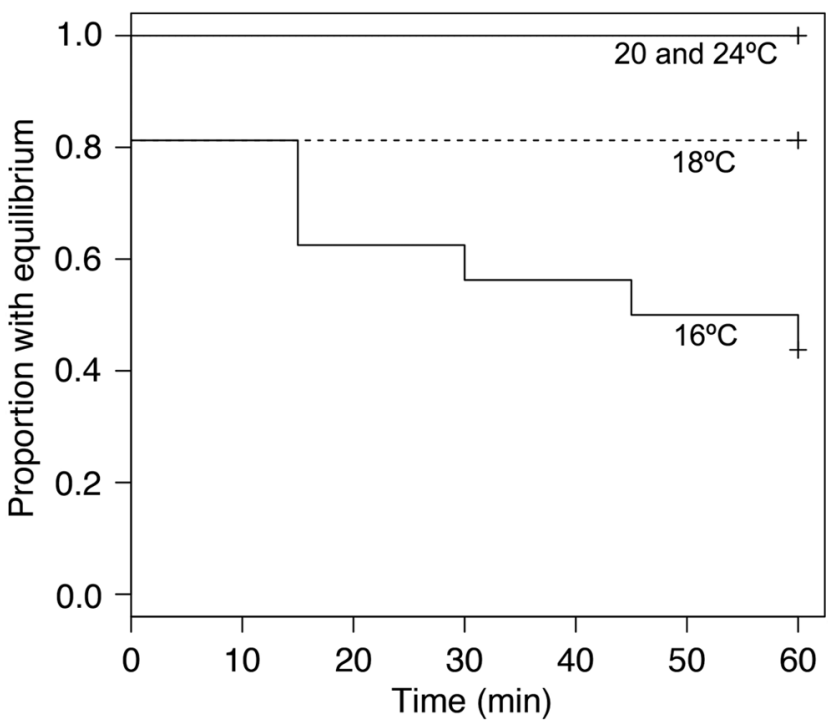

Fig. 2. Proportion of mottled mojarra that lost equilibrium during the exposure period across temperature treatments

tinued to experience reflex impairment (Fig. 3), which was more severe at $16^{\circ} \mathrm{C}$ (Table 1). After the cold shock exposure period, fish in all treatments had zero RAMP impairment, and those exposed to $16^{\circ} \mathrm{C}$ exhibited the best swimming performance, with the longest chase times and most lines crossed of any treatment (Fig. 4). There was a significant effect of 


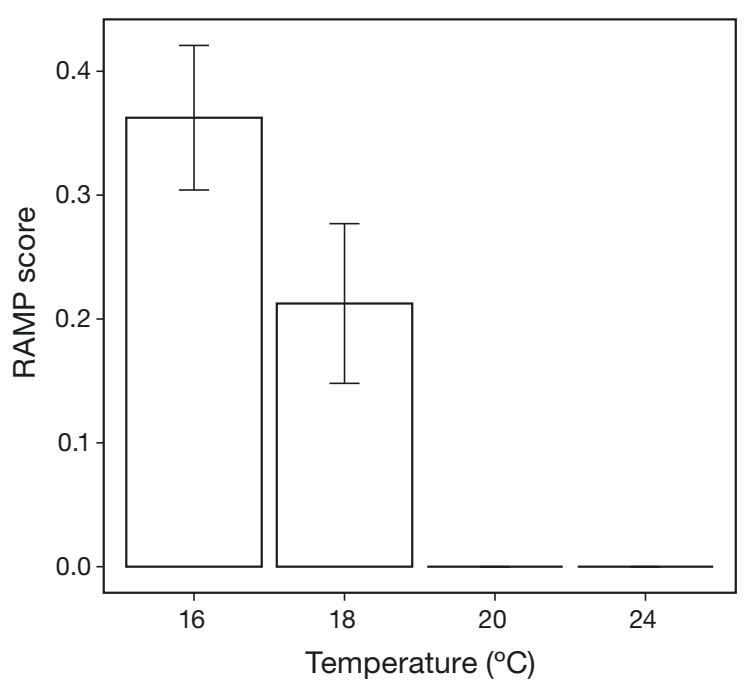

Fig. 3. Reflex Action Mortality Predictor (RAMP) score ( \pm SE) for mottled mojarra immediately after exposure to a range of temperatures for $60 \mathrm{~min}$

Table 1. Proportion of mottled mojarra that exhibited reflex impairment after 60 min of cold shock exposure at 16 or $18^{\circ} \mathrm{C}$. RAMP: Reflex Action Mortality Predictors; VOR: vestibular-ocular response

\begin{tabular}{lcc|}
\hline RAMP & $16^{\circ} \mathrm{C}$ & $18^{\circ} \mathrm{C}$ \\
\hline Body flex & 0.81 & 0.38 \\
Tail grab & 0.25 & 0.31 \\
VOR & 0.13 & 0.00 \\
Equilibrium & 0.19 & 0.19 \\
Head complex & 0.44 & 0.25 \\
\hline
\end{tabular}

treatment on the amount of time chased $\left(F_{3,60}=3.6\right.$, $\mathrm{p}=0.02)$; mottled mojarra in the $16^{\circ} \mathrm{C}$ treatment swam significantly longer than those in the 18 and $20^{\circ} \mathrm{C}$ treatments $(\mathrm{p}<0.05$; Fig. 4 ). There was also a significant effect of treatment on the number of lines crossed $\left(F_{3,60}=4.1, \mathrm{p}=0.01\right)$; fish in the $16^{\circ} \mathrm{C}$ treatment crossed significantly more lines than those in the $18^{\circ} \mathrm{C}$ treatment $(p=0.01)$. After the chase to exhaustion, all fish exhibited impaired tail grab response (integral to the chasing process), but no other RAMP impairment.

\section{DISCUSSION}

Abrupt declines in water temperature had significant impacts on the ventilation rates, reflexes, and swimming performance of mottled mojarra. Ventilation rates displayed some surprising patterns, where
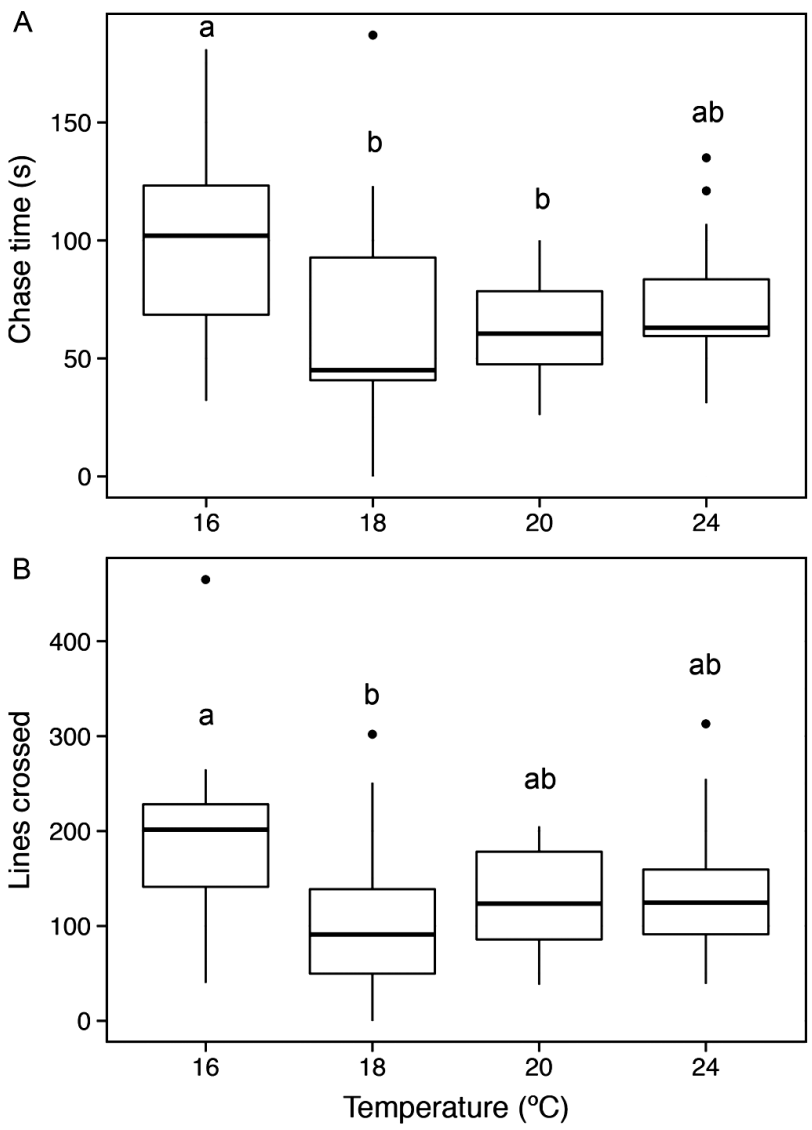

Fig. 4. (A) Time chased and (B) number of lines crossed by mottled mojarra after a 60 min exposure to various temperatures. Boxes: 1st and 3rd quartiles; horizontal lines: medians; whiskers: $1.5 \times$ inner quartile range; dots: outliers. Dissimilar letters indicate statistically significant differences between treatments using Bonferroni-corrected pairwise $t$-tests

at relatively moderate decreases in temperature (18 and $20^{\circ} \mathrm{C} ; 4$ and $6^{\circ} \mathrm{C}$ below ambient), mottled mojarra exhibited higher ventilation rates than at ambient, while at the greatest decline in temperature $\left(16^{\circ} \mathrm{C} ; 8^{\circ} \mathrm{C}\right.$ below ambient) fish had similar ventilation rates to ambient. Abrupt changes in temperature typically cause physiological disturbances that increase metabolic demands in ectotherms (Wendelaar Bonga 1997, Jentoft et al. 2005, Donaldson et al. 2008), which is likely why mottled mojarra exhibited increased ventilation rates at 18 and $20^{\circ} \mathrm{C}$. However, some fish species can compensate physiologically to abrupt declines in temperature (Fry 1947, Shiels et al. 2003, Narum et al. 2013), which may explain why ventilation rates remained similar in fish exposed to $16^{\circ} \mathrm{C}$ to those at ambient temperature (Fig. 1). However, it is surprising that such compensation would not occur at lesser degrees of temperature change. Ventilation rates are often assumed to be reflective of 
cardio-respiratory demand, but there is growing evidence to suggest that when exposed to stressors, ventilation rates may not always be a strong predictor of physiological status (Barreto \& Volpato 2004).

A decline in temperature of $4^{\circ} \mathrm{C}$ caused significantly higher ventilation rates, but mottled mojarra exhibited no equilibrium loss during exposure, nor any other reflex impairment after the $1 \mathrm{~h}$ exposure period. Conversely, declines of 6 and $8^{\circ} \mathrm{C}$ caused rapid equilibrium loss and significant reflex impairment, particularly at $8^{\circ} \mathrm{C}$ below ambient temperature. Equilibrium loss is a common result of cold shock exposure in fish, and is an indication of physiological stress that may lead to mortality (Griffith 1978, Hyvärinen et al. 2004, Donaldson et al. 2008, Davis 2010, Raby et al. 2012). Loss of ability to swim upright also greatly reduces the capacity of fish to move into deeper water to escape further cold exposure (in the case of storm-induced perturbation of shallow waters) or avoid predators, further increasing the probability of mortality. Interestingly, tidal creek environments in Eleuthera (where fish were collected for this study) experience daily fluctuations of up to $11^{\circ} \mathrm{C}$ (Murchie et al. 2011), while the lower sub-lethal thermal limit for mottled mojarra in this study was $12^{\circ} \mathrm{C}$ on average. However, the cold shock scenarios tested here exposed fish to more abrupt declines in temperature that may be more similar to those resulting from storms or ocean upwelling than typical diel patterns associated with tidal cycles and solar radiation.

Post-exposure swimming capabilities yielded some surprising results: $30 \mathrm{~min}$ after $1 \mathrm{~h}$ of exposure to 4 and $6^{\circ} \mathrm{C}$ temperature declines, mojarra exhibited similar swimming capabilities to those maintained at ambient temperature, while those exposed to $8^{\circ} \mathrm{C}$ declines actually swam longer and crossed more lines than those in the other treatments. Despite the fact that mottled mojarra experienced significant reflex impairment at more severe temperature declines during exposure, swimming performance quickly returned after a $30 \mathrm{~min}$ recovery period at ambient temperature. Exposure to cold shock initiates a physiological stress response, a component of which is increased capacity to deliver oxygen to muscles, and an increase in available energy reserves (Wendelaar Bonga 1997, Shiels et al. 2003). This may explain why, when placed back into water at ambient temperature, mottled mojarra exposed to $8^{\circ} \mathrm{C}$ colder water had similar, if not greater swimming capabilities compared to other treatments. This is consistent with findings in another subtropical marine species, the bonefish (Albula vulpes; Szekeres et al. 2014), which collectively supports the concept that if fish are able to escape cold water during cold shock events, swimming capabilities quickly return and the chances of mortality due to predation are minimal. However, the ability of fish to escape near-shore areas affected by cold shock events (e.g. upwellings or storms) ultimately depends on the behaviour of the fish and the nature of the environment. In environments such as Kemps Creek in Eleuthera, with its expansive shallow flats, fish must travel long distances to reach deeper water.

In summary, exposing mottled mojarra to abrupt cold shock caused significant behavioural impairment; the level of impairment was generally associated with the magnitude of temperature change. Exposure to 16 and $18^{\circ} \mathrm{C}$ ( 8 and $6^{\circ} \mathrm{C}$ below ambient) caused significant reflex impairment, potentially reflecting a physiological stress response. Indeed, extended exposure to water $>4^{\circ} \mathrm{C}$ below ambient may cause mortality in this species. However, if mottled mojarra are able to escape abrupt declines in temperature, swimming capabilities are quickly regained and therefore predation risk would likely be low. To date, very little research has focused on the consequences of cold shock on tropical or subtropical species. Future studies should extend our understanding of the impacts of cold shock to other species in these areas, including critical thermal thresholds and durations. Moreover, there is a need for research on the impacts of cold shock on a greater size range of individuals, especially smaller fish, which may be more sensitive to temperature variability (Donaldson et al. 2008). Such research would be timely, given that adverse weather conditions and changes in ocean currents driven by global climate change may expose near-shore dwelling tropical fish species to increasingly frequent cold shock events in the coming decades.

Acknowledgements. We thank the staff at Cape Eleuthera Institute for supporting our research. J.W.B. was supported by the Natural Sciences and Engineering Research Council of Canada (NSERC). S.J.C. was supported by the Canada Research Chair's program and NSERC. E.S. was supported by the University of Manchester with travel support from NSERC.

\section{LITERATURE CITED}

Bakun A (1990) Global climate change and intensification of coastal ocean upwelling. Science 247:198-201

Barreto RE, Volpato GL (2004) Caution for using ventilatory frequency as an indicator of stress in fish. Behav Process $66: 43-51$ 
Brett JR (1971) Energetic responses of salmon to temperature. A study of some thermal relations in the physiology and freshwater ecology of sockeye salmon (Oncorhynchus nerkd). Am Zool 11:99-113

Brownscombe JW, Thiem JD, Hatry C, Cull F, Haak CR, Danylchuk AJ, Cooke AJ (2013) Recovery bags reduce post-release impairments in locomotory activity and behavior of bonefish (Albula spp.) following exposure to angling-related stressors. J Exp Mar Biol Ecol 440: 207-215

> Brownscombe JW, Nowell L, Samson E, Danylchuk AJ, Cooke SJ (2014) Fishing-related stressors inhibit refugeseeking behaviour in released sub-adult great barracuda Sphyraena barracuda. Trans Am Fish Soc 143:613-617

Cooke SJ, Messmer V, Tobin AJ, Pratchett MS, Clark TD (2014) Refuge-seeking impairments mirror metabolic recovery following fisheries-related stressors in the Spanish flag snapper (Lutjanus carponotatus) on the Great Barrier Reef. Physiol Biochem Zool 87:136-147

Davis MW (2010) Fish stress and mortality can be predicted using reflex impairment. Fish Fish 11:1-11

> Donaldson MR, Cooke SJ, Patterson DA, Macdonald JS (2008) Cold shock and fish. J Fish Biol 73:1491-1530

> Donelson JM, Munday PL, McCormick MARK, Nilsson GE (2011) Acclimation to predicted ocean warming through developmental plasticity in a tropical reef fish. Glob Change Biol 17:1712-1719

Eme J, Bennett WA (2009) Critical thermal tolerance polygons of tropical marine fishes from Sulawesi, Indonesia. J Therm Biol 34:220-225

Fangue NA, Bennett WA (2003) Thermal tolerance responses of laboratory acclimated and seasonally acclimatized Atlantic stingray, Dasyatis sabina. Copeia 2003:315-325

FWCC (Fish and Wildlife Conservation Commission) (2010) Snook cold kill report. Fish and Wildlife Research Institute, St. Petersburg, FL

Fry FEJ (1947) Effects of the environment on animal activity. Publications of the Ontario Fisheries Research Laboratory No. 68, University of Toronto Studies Biological Series No. 55. University of Toronto Press, Toronto

> Griffith JS (1978) Effects of low temperature on the survival and behaviour of threadfin shad, Dorosoma petenense. Trans Am Fish Soc 107:63-70

Haverinen J, Vornanen M (2007) Temperature acclimation modifies sinoatrial pacemaker mechanism of the rainbow trout heart. Am J Physiol 292:R1023-R1032

Hyvärinen P, Heinimaa S, Rita H (2004) Effects of abrupt cold shock on stress responses and recovery in brown trout exhausted by swimming. J Fish Biol 64:1015-1026

IPCC (2007) Summary for policymakers. In: Solomon SD, Qin M, Manning Z, Chen M and others (eds) Climate change 2007: the physical science basis. Contribution of Working Group I to the Fourth Assessment Report of the Intergovernmental Panel on Climate Change. Cambridge University Press, Cambridge

$>$ Jentoft S, Aastveit AH, Torjesen PA, Andersen Ø (2005) Effects of stress on growth, cortisol and glucose levels in non-domesticated Eurasian perch (Perca fluviatilis) and domesticated rainbow trout (Oncorhynchus mykiss). Comp Biochem Physiol Part A Mol Integr Physiol 141:353-358

Kerschner BA, Peterson MS, Gilmore RG Jr (1985) Ectopic and ontogenetic trophic variation on mojarras (Pisces: Gerreidae). Estuaries 8:311-322

Lamadrid-Rose Y, Boehlert GW (1988) Effects of cold shock on egg, larval, and juvenile stages of tropical fishes: potential impacts of ocean thermal energy conversion. Mar Environ Res 25:175-193

Larsen TH, Brehm G, Navarrete H, Franco P, Gomez H (2011) Range shifts and extinctions driven by climate change in the tropical Andes: synthesis and directions. In: Herzog SK, Martínez R, Jørgensen PM, Tiessen H (eds) Climate change and biodiversity in the tropical Andes. Inter-American Institute for Global Change Research (IAI) and Scientific Committee on Problems of the Environment (SCOPE), p 47-67

Meyer-Rochow VB (2013) Thermal pollution: general effects and effects on cellular membranes and organelles in particular. In: Allodi S, Nazari EM (eds) Exploring themes on aquatic toxicology. Research Signpost Publishing, Trivandrum, p 1-34

Michener WK, Blood ER, Bildstein KL, Brinson MM, Gardner LR (1997) Climate change, hurricanes and tropical storms, and rising sea level in coastal wetlands. Ecol Appl 7:770-801

> Montgomery JC, Macdonald JA (1990) Effects of temperature on nervous system: implications for behavioral performance. Am J Physiol 259:R191-R196

Munday PL, Jones GP, Pratchett MS, Williams AJ (2008) Climate change and the future for coral reef fishes. Fish Fish 9:261-285

> Murchie KJ, Cooke SJ, Danylchuk AJ, Danylchuk SE, Goldberg TL, Suski CD, Philipp DP (2011) Thermal biology of bonefish (Albula vulpes) in Bahamian coastal waters and tidal creeks: an integrated laboratory and field study. J Therm Biol 36:38-48

Narum SR, Campbell NR, Meyer KA, Miller MR, Hardy RW (2013) Thermal adaptation and acclimation of ectotherms from differing aquatic climates. Mol Ecol 22: 3090-3097

Newman SP, Handy RD, Gruber SH (2012) Ontogenetic diet shifts and prey selection in nursery bound lemon sharks, Negaprion brevirostris, indicate a flexible foraging tactic. Environ Biol Fishes 95:115-126

> Nilsson GE, Crawley N, Lunde LG, Munday PL (2009) Elevated temperature reduces the respiratory scope of coral reef fishes. Glob Change Biol 15:1405-1412

Pinheiro JC, Bates DM (2000) Mixed-effects models in S and S-PLUS. Springer, New York, NY

Portz DE (2007) Fish-holding-associated stress in Sacramento river chinook salmon (Oncorhynchus tshawytscha) at South Delta fish salvage operations: effects on plasma constituents, swimming performance, and predator avoidance. $\mathrm{PhD}$ dissertation, University of California, San Diego, CA

> Prosser L, Farhi E (1965) Effects of temperature on conditioned reflexes and on nerve conduction in fish. Z Vgl Physiol 50:91-101

R Core Team (2012). R: A language and environment for statistical computing. R Foundation for Statistical Computing, Vienna

Raby GD, Donladson MR, Hinch SG, Patterson DA and others (2012) Validation of reflex indicators for measuring vitality and predicting the delayed mortality of wild coho salmon bycatch released from fishing gears. J Appl Ecol 49:90-98

> Roessig JM, Woodley CM, Cech JJ, Hansen LJ (2004) Effects of global climate change on marine and estuarine fishes and fisheries. Rev Fish Biol Fish 14:251-275 
Roots BI, Prosser CL (1962) Temperature acclimation and the nervous system in fish. J Exp Biol 39:617-629

> Shiels HA, Vornanen M, Farrell AP (2003) Acute temperature change modulates the response of ICA to adrenergic stimulation in fish cardiomyocytes. Physiol Biochem Zool 76:816-824

Szekeres P, Brownscombe JW, Cull F, Danylchuk AJ and others (2014) Physiological and behavioural conse-

Editorial responsibility: Victor Meyer-Rochow, Bremen, Germany quences of cold shock on bonefish (Albula vulpes) in The Bahamas. J Exp Mar Biol Ecol 459:1-7

Wendelaar Bonga SEW (1997) The stress response in fish. Physiol Rev 77:591-625

Wilson SK, Adjeroud M, Bellwood DR, Berumen ML, Booth D, Bozec YM, Syms C (2010) Crucial knowledge gaps in current understanding of climate change impacts on coral reef fishes. J Exp Biol 213:894-900

Submitted: June 25, 2014; Accepted: October 8, 2014

Proofs received from author(s): December 4, 2014 